\title{
Article \\ The Physio-Psychological Effect of Forest Therapy Programs on Juvenile Probationers
}

\author{
Jin Young Jeon ${ }^{1} \mathbb{C}$, In Ok Kim ${ }^{1}$, Poung-sik Yeon ${ }^{2}$ and Won Sop Shin ${ }^{2, *(\mathbb{D}}$ \\ 1 Department of Forest Therapy, Chungbuk National University, Cheongju 28644, Korea; \\ forest-bb@naver.com (J.Y.J.); inoya88@hanmail.net (I.O.K.) \\ 2 Department of Forest Sciences, Chungbuk National University, Cheongju 28644, Korea; \\ imoscow@hanmail.net \\ * Correspondence: shinwon@chungbuk.ac.kr; Tel.: +82-43-261-2536
}

Citation: Jeon, J.Y.; Kim, I.O.; Yeon, P.-s.; Shin, W.S. The

Physio-Psychological Effect of Forest Therapy Programs on Juvenile Probationers. Int. J. Environ. Res. Public Health 2021, 18, 5467. https:// doi.org/10.3390/ijerph18105467

Academic Editors: Matt DeLisi and Po-See Chen

Received: 18 December 2020

Accepted: 11 May 2021

Published: 20 May 2021

Publisher's Note: MDPI stays neutral with regard to jurisdictional claims in published maps and institutional affiliations.

Copyright: (c) 2021 by the authors. Licensee MDPI, Basel, Switzerland. This article is an open access article distributed under the terms and conditions of the Creative Commons Attribution (CC BY) license (https:// creativecommons.org/licenses/by/ $4.0 /)$.

\begin{abstract}
The study aimed to investigate the psychological and physiological effects of forest therapy programs on adolescents under probation. Fifty probationary teenagers from the Ministry of Gyeonggi Justice Compliance Support Center participated in the study. The study explored the effectiveness of a nonrandomized control group pretest-posttest design forest therapy program. The forest therapy program was conducted for two days and one night for the experimental groups $(\mathrm{N}=33)$, who participated in the forest therapy program, and the control group $(\mathrm{N}=17)$, who received two days of attendance center orders program in the lecture room of the Ministry of Gyeonggi Justice Compliance Support Center. As a result, adolescents under probation who participated in forest therapy programs had a beneficial effect on psychological well-being (K-WBMMS) and HRV's HF (high frequency) and LF/HF (A ratio of Low Frequency to High Frequency) compared to those who received the general attendance center orders program. These results support that forest therapy programs play a positive role in the psychological and physiological effects of probationary adolescents and can affect the diversity of rehabilitation programs for probationary adolescents.
\end{abstract}

Keywords: juvenile delinquents; adolescents; forest therapy; anti-recidivism programs; psychological well-being; HRV

\section{Introduction}

Delinquency, which was previously limited to unsupervised wandering, has emerged as a serious social problem as the proportion of violent crimes such as theft, school violence, group sexual assault, and murder has increased daily. Since 1989, South Korea has implemented a probation system that improves criminality in accordance with volunteer activities and attendance center orders, while living a normal life at home, school, and the workplace, and without imprisoning teenagers who commit crimes [1]. In the case of juvenile crimes, the premise is that these individuals are not fully developed when compared to adults; therefore, delinquency is managed through protection and education, rather than strong punishment [2].

Youth crime rates continue to decline due to the efforts of programs for adolescents under probation. In 2018, the number of probationary teenagers stood at $35,626,4.2 \%$ less than that in the previous year. Also, the proportion of teenagers who received their first probation in the past decade accounted for $48.3 \%$ in 2018 , compared to $66.1 \%$ in 2009 [3]. However, unlike the declining trend of probationary teenagers, there remains work to be done regarding juvenile delinquency. According to the crime white paper of the Ministry of Justice [4], the proportion of crimes by women is increasing based on the status of probation in 2018, and 16- to 17-year-olds account for the highest percentage of all criminal and special law crimes. The highest numbers of charges were for theft $(11,625 ; 34.9 \%)$ and violence $(4207 ; 12.6 \%)$. In particular, the biggest problem is that approximately $90 \%$ of all repeat offences occur within a year. In 2018, Korea's crime rate for probationary teenagers was 
$15.7 \%$ within one month, $24.1 \%$ within three months (one to three months), $23.4 \%$ within six months (three to six months), and $26.4 \%$ within a year (six months to one year), with a total crime rate of $89.6 \%$. This shows that the target number of probationary teenagers is much higher than that of adults. To solve these problems, an important strategy involves improving the attendance center order programs for probationary youth.

Adolescence is the stage of life in which people experience the most risks, opportunities, frustrations, and achievements [5]. According to Ryff [6], psychological well-being is the sum of psychological aspects constituting an individual's quality of life. People with a high quality of life accept themselves as they are and maintain positive interpersonal relationships. They can control their behavior, surrounding, sense of purpose, and motivation to reveal their potential [7]. Armsden and Greenberg [8] reported adolescents with healthy attachments to parents and peers reported higher self-esteem and life satisfaction; occurrences of depression, anxiety, guilt, anger, alienation, and self-concept confusion were lower. Kim et al. [9] reported that these relationships add to the experience of school life, as good relationships are related to high satisfaction with school. Psychological well-being in adolescence allows young people to grow and form their judgments independently. Receiving good social support from relationships with family and peers are important factors that affect personal development and psychological health [10-12].

However, compared to adolescents who come from stable environments, juvenile offenders usually hail from vulnerable environments, where their psychological, familial, peer group and social resources are insufficient for healthy growth and development. Difficulties in emotional support due to specific family structures such as single parents, divorce, or remarriage [13-15], inconsistent parenting [16,17], deviant peer on delinquency [18], depression [19,20], low self-concept [21], impulsiveness, and aggression [22-24] are factors that increase juvenile delinquency. It is expected that criminals in this situation experience low levels of happiness and high levels of psychological anxiety. The stigma of being labeled a criminal is a stressor for juvenile offenders and is related to their depression and low self-esteem [25,26]. Low self-esteem is a powerful influencer of violent behavior [27]. According to Lim et al. [28], the negative emotional experience of juvenile offenders affects impulsive behavior and aggression, which directly affects delinquency. If juvenile delinquents fail to properly deal with stress reactions such as depression, dissatisfaction, social contraction, and aggression, they will show problems such as drinking, drug use, running away from home, suicide, and smoking $[29,30]$. The continuation of this life can be said to affect the stress control of juvenile offenders.

The influence of stress may vary depending on how stress coping resources control stress [31]. High levels of stress coping resources in stressful situations can buffer the negative effects of stress. However, juvenile delinquents who have lower stress response capabilities than ordinary teenagers are bound to be poor at coping with stress, which can negatively affect even physical reactions. Stress and physical symptoms showed a static correlation $[32,33]$. Stress reactions can be identified through autonomic neuronal activity. In situations such as negative emotions or stress imposition, sympathetic nerve activity increases, and parasympathetic nerves are activated when positive emotions are triggered. If a stressful situation persists, it is difficult to maintain a balanced life between mind and body. Therefore, it is necessary to properly manage the emotional tension of juvenile delinquents to relieve stress-induced physical tension.

However, the current attendance center orders require a professional program that deals with emotional and physical stability as much as retraining to prevent re-offending and help young probationers develop healthy growth in the form of group therapy such as mental development training, human relationships, sex education, and substance abuse education [34]. To this end, the Ministry of Justice actively links government ministries and private resources to promote more effective delinquent behavior correction and prevention of recidivism through experiential learning, volunteer work, cultural arts programs, etc. Recently, a program has been developed to help the unstable situation of probationary youth considering their characteristics [35-38]. Attempts by various programs, such as 
mentoring, art therapy, and meditation, have shown effects such as stabilizing emotions, reducing impulsiveness and aggression, and improving empathy among teenagers, and as a result, factors affecting delinquent behavior have improved.

According to a report by Lee et al [39], subjective evaluations of probationary adolescents were conducted on the attendance center orders program. As a result, leisure culture and hobby-based activities were most helpful in reducing delinquency behavior and stabilizing psychology and emotions. Motivation for participation was also found to have a higher preference for dynamic activities centered on experience or play than lecture ceremonies. Probationary teenagers are being treated in the form of internal treatment. The need to develop various programs aimed at recovering risk factors for youth, such as self-esteem, sociality, and mental balance, is constantly mentioned to overcome difficulties in daily life and to return to society smoothly.

Interest in forest activity intervention is increasing day by day to help teenagers participate in effective attendance center order programs. Forest activities are known to play a positive role as a space for psychological and physical recovery. It has been reported that forest activities relieve negative emotions, such as depression and anger [40-42] and provide stress recovery [43-45]. These positive psychological effects create positive physiological effects, such as parasympathetic nerve activation [42,46-49] and stress hormone reduction $[49,50]$. In addition to solely experiencing the forest, research on the effectiveness of mental and physical health promotion activities is also underway through a program that is systematically organized using the sounds, scents, landscapes, and natural objects of the forest. This is also applicable to forest therapy programs for teenagers.

Forest therapy programs use physical activities and psychotherapy to help improve the health of adolescents. Forest activities can give physical energy to teenagers. Through various activities using natural objects, teenagers experience a sense of achievement, fun, and immersion, and improve their concentration. Through this, teenagers' confidence and personal capabilities can be increased, and their interpersonal capabilities can be enhanced through cooperation and intimacy with the members who worked together [51]. According to Chang et al. [52], forest experience programs have been shown to help adolescents adapt and cope by reducing depression and anxiety and positively impacting their selfconcept. Cho et al. [53] conducted forest education programs in spring, summer, and autumn and showed improvements in adolescents' psychological well-being and reduction of stress levels, regardless of the season. Forest education programs also appear to effect physiological changes. Lee [54] studied the impact of Natural Park experiences on heart rate variability (HRV) and found that parasympathetic nerve activity was activated and sympathetic nerve activity, which is activated under stress, was inhibited. Furthermore, Chung et al. [55] studied a three-night and four-day forest therapy camp, considered to be a special group, and found changes in resilience, interpersonal relationships, and heart rate intervals. It was revealed that the forest experience not only had a positive impact on adolescents' development of social sentiments, such as emotional acceptability and improved emotional control, but also provided physiological stability.

Studies of juvenile offenders with forest experience also showed potential psychological healing [56-60]. A study by Eom et al. [56] reported that a two-day forest education program had a positive effect on the mood, self-esteem, and self-control of probationary youth. Jang et al. [57] reported that forest education programs showed positive changes in self-esteem and resilience. Walsh [58] reported that program activities in nature have shown great changes in young offenders' hopes, resilience, and self-efficacy.

These previous studies show that forest therapy helps develop prosocial connections and bonds and introduces positive psychological and physiological stimuli for juvenile offenders. However, there is still a lack of underlying research to help young people with psychological and physical stability through forest therapy programs, and more evidence on health benefits is needed. Therefore, this study aimed to investigate whether forest therapy developed by referring to the characteristics of probationary adolescents affected their psychological and physical conditions. 
Hypothesis 1. Adolescents under probation who have experienced forest therapy programs will see a greater positive change in their psychological well-being in comparison to those who have attendance center orders.

Hypothesis 2. Adolescents under probation who have experienced forest therapy programs will show a greater positive change in HRV than those who have attendance center orders.

\section{Materials and Methods}

\subsection{Participants}

The program was conducted with 50 juvenile probationers from the Gyeonggi Justice Compliance Support Center. This study was conducted with the approval of the IRB (CBNU-201809-SB-711-01) of Chungbuk National University Industry-Academic Cooperation Foundation. The researcher made a recruitment announcement to a Justice Compliance Support Center in Korea to conduct a forest therapy program for probationary youth. After a meeting with a Justice Compliance Support Center that expressed its willingness to participate in the program and the overall progress of the program, the probationary youth were notified of the recruitment. Participants were selected from those who completed a voluntary participation agreement after explaining the purpose and content of the study. The forest therapy program was conducted in different groups of participants, and in the case of the experimental group, the two-day, one-night program was divided into 8 people in the first, 9 people in the second, and 13 people in the third. The control group had 17 participants in two days.

Most of the juvenile probationers who participated in the study identified as "male" $(92.5 \%)$. The age range was 15 to 20 years old. The average age of the experimental group was 16.4 years, and of the control group was 15.8 years. Participants included 14 middle school students (experimental group $N=8$, control group $N=6$ ) and 36 high school students (experimental group $N=25$, control group $N=11$ ). An overview of the demographic data is shown in Table 1.

Table 1. Demographic characteristics of experimental and control groups.

\begin{tabular}{|c|c|c|c|c|}
\hline \multicolumn{2}{|c|}{ Classification } & \multirow{3}{*}{$\begin{array}{c}\text { Experiment Group }(N=33) \\
N(\%)\end{array}$} & \multirow{3}{*}{$\begin{array}{c}\text { Control Group }(N=17) \\
N(\%)\end{array}$} & \multirow{3}{*}{$\begin{array}{c}\text { Total } \\
N(\%) \\
47(100.0 \%) \\
3(100.0 \%)\end{array}$} \\
\hline & Male & & & \\
\hline Sex & Female & & & \\
\hline Age average & 1999-2003 & 16.4 & 15.8 & 16.1 \\
\hline \multirow{2}{*}{$\begin{array}{c}\text { Academic } \\
\text { Background }\end{array}$} & $\begin{array}{l}\text { Middle school } \\
\text { enrolled }\end{array}$ & $8(55.0 \%)$ & $6(45.0 \%)$ & $14(100.0 \%)$ \\
\hline & $\begin{array}{l}\text { High school } \\
\text { enrolled }\end{array}$ & $25(71.5 \%)$ & $11(28.5 \%)$ & $36(100.0 \%)$ \\
\hline
\end{tabular}

\subsection{Experimental Sites}

The Saneum Healing Forest is the first healing forest in Korea. It is composed of various tree species, such as pine (Pinus Densiflora Siebold \& Zucc), larch (larix kaempferi (Lamb.) Carrière), and ash (fraxinus rhynchophylla), among others. The natural environment is excellent. The altitude of Saneum Healing Forest varies from about 200 to $1000 \mathrm{~m}$, making it suitable for forest therapy programs using climate and exercise therapy. The valley, which has abundant water resources, is located around the Health Promotion Center. By generating anions, Healing Forest Road is known to make people feel increased immune health, mental stability, and freshness. The Saneum Healing Forest is a suitable destination for forest therapy based in sensory programs (see Figure 1). 


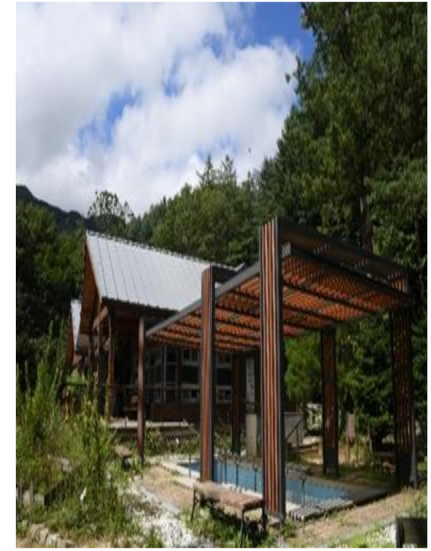

(a) The Saneum Healing Forest Health Promotion Center

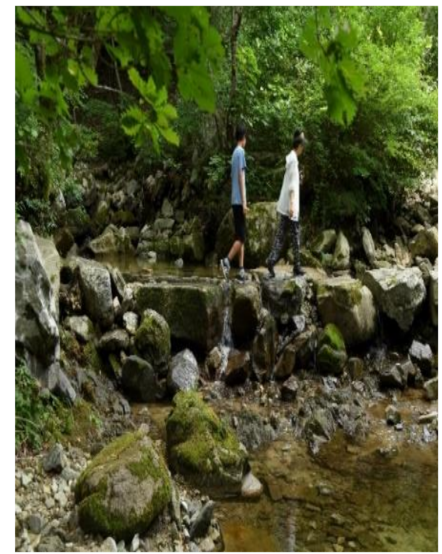

(b) A trail along the valley

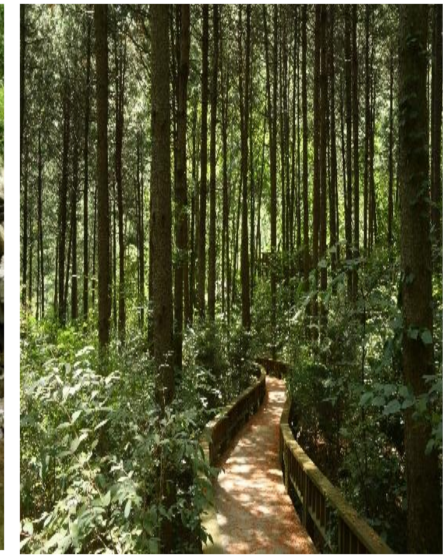

(c) A pine grove road

Figure 1. The Saneum Healing Forest.

\subsection{Procedure}

The forest therapy program ran from August to September 2018. The study explored the effectiveness of a non-randomized control group pretest-post-test design forest therapy program. The forest therapy program was conducted for two days and one night for the experimental groups $(\mathrm{N}=33)$, who participated in the forest therapy program, and the control group $(\mathrm{N}=17)$, who received two days of an attendance center orders program. A pretest measurement was conducted before the forest therapy program began. On the first day, participants arrived at the Healing Forest Center to understand the questionnaire, fill out the psychological well-being questionnaire, and measure their HRV. After the pretest, the schedule for the next two days and one night was introduced, with precautions for safety. Participants placed their luggage in their accommodations, finished their lunches, took a break, and began the forest therapy program. After the first day of the program, they stayed overnight at the Saneum Recreation Forest and proceeded with the program the next morning. After sharing their impressions, the program ended. The questionnaires were filled in and HRV was measured. After these were completed, the participants returned home with a probation officer.

The program consisted of three themes, and its purpose was to observe positive psychological and physical changes through activities in the forest. The first theme, "Go to the Forest" ("body, hello!", "introduce myself using natural objects"), was designed to raise interest in forests, form intimacy between participants, and prepare participants to adapt to the new environment. The second theme, "Do in the Forest" ("sense awakening walk", "dream of trees", "my dream", "meditation with walking in forest: slow pace", "looking at the sky", and "night walk in the forest") aimed at relaxing the mind and body through walking in the forest and meditating in the forest environment through five senses. Moreover, they were encouraged to reflect on the past and think about the future. The final theme, "With the Forest and Well" ("storytelling: my dream", "phytoncide breathing meditation", "hammock healing", "scent of forest therapy), was designed to provide an opportunity to define dreams and visions for the future (see Figure 2). 


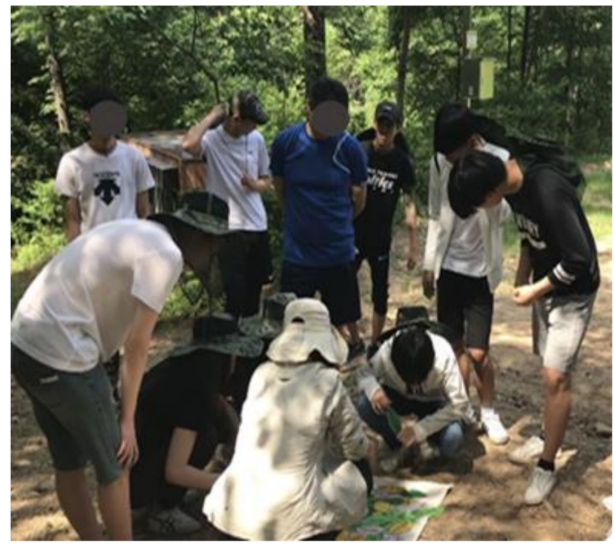

(a) Using an adjective card to select selecting a card to introduce oneself during the program

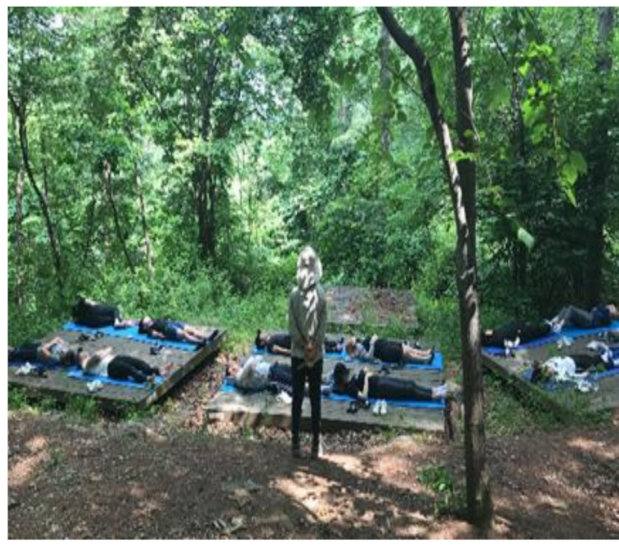

(c) Sufficiently relaxed through the "looking at the sky" program

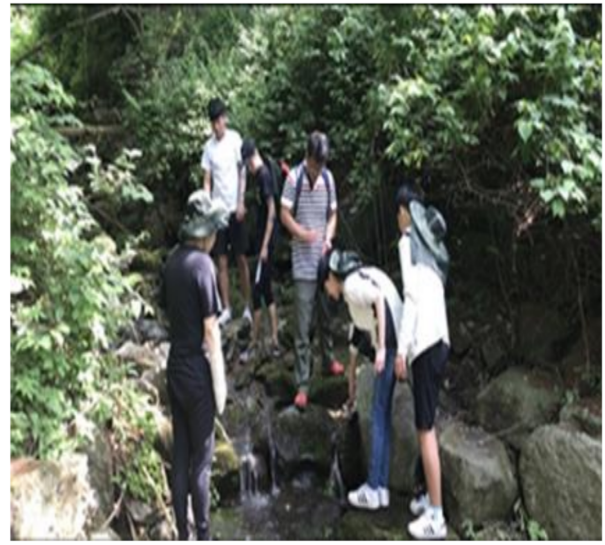

(b) Focusing on the sound of a valley during the "sense awakening walk" program

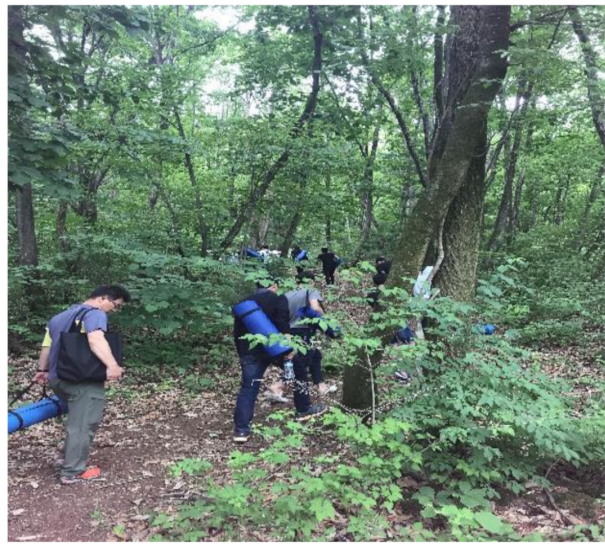

(d) "Meditation with walking in forest" to concentrate on oneself and meditate while walk

Figure 2. Major progress of forest therapy program.

The forest therapy program was conducted by two forest therapy instructors. Two probation officers participated in the program to encourage lagging participants. They participated in the play to increase the participants' immersion and to safeguard the participants. Each program's progress time and unit program were adjusted according to the participant's immersion or condition. Detailed forest therapy program activities were scheduled as shown in Table 2. Participants in the control group visited the Ministry of Justice Compliance support center for two days and were required to carry out the attendance center orders program. Pre- and post-measurements were performed in the same way as the experimental group. The control group was instructed to continue general life routines, except for visiting the natural environment. 
Table 2. Forest therapy program.

\begin{tabular}{|c|c|c|}
\hline Time & Day 1 & Day 2 \\
\hline 07:00- & & $\begin{array}{c}\text {-Get up } \\
\text {-Morning walk }\end{array}$ \\
\hline 08:00-09:00 & & Breakfast \\
\hline 09:00-11:00 & & $\begin{array}{l}\text {-Storytelling: my dream } \\
\text {-Hammock healing } \\
\text {-Scent of forest therapy }\end{array}$ \\
\hline 11:00-12:30 & $\begin{array}{l}\text {-Orientation and fill in the consent form } \\
\text {-Physiological and psychological pretest }\end{array}$ & $\begin{array}{l}\text {-Physiological and } \\
\text { psychological posttest }\end{array}$ \\
\hline 12:30-13:30 & Lunch & Lunch \\
\hline 13:30-14:00 & Check in & \\
\hline 14:00-15:00 & $\begin{array}{l}\text {-Body, hello! (Forest gym exercise) } \\
\text {-Introduce myself using natural objects }\end{array}$ & \\
\hline 15:00-15:40 & Sense awakening walk & \\
\hline $15: 40-16: 20$ & $\begin{array}{l}\text {-Dream of trees (investigating organic and } \\
\text { dynamic ecological links of forest) } \\
\text {-My dream (cutting logs and watching their } \\
\text { growth rings) }\end{array}$ & \\
\hline 16:20-17:00 & Meditation with walking in forest: slow pace & \\
\hline 17:00-18:00 & Looking at the sky & \\
\hline 18:00-19:30 & Dinner & \\
\hline 19:30-20:50 & Night walk in the forest & \\
\hline $20: 30-$ & Free time and off to dream land & \\
\hline
\end{tabular}

\subsection{Measurement}

\subsubsection{Psychological Well-Being (Well-Being Manifestation Measure Scale)}

To measure the psychological well-being of adolescents, Park and Choi [61] translated and calibrated into Korean the Well-Being Manifestation Measure Scale developed by Masse et al. [62]. The subfactor of this scale is the five-point Likert scale $(1=$ strongly disagree; 5 = strongly agree), consisting of a total of six subfactors and 25 questions measuring self-esteem, mental balance, sociability, social involvement, control of self and events, and happiness. The higher the score of each question, the higher the level of psychological well-being of adolescents. The Cronbach's $\alpha$ of the original measurement was 0.92 .

\subsubsection{HRV}

The HRV test is a method of measuring the reaction of the autonomic nervous system. The sympathetic nervous system is activated during experiences of tension and stress, and the parasympathetic nervous system activates during relaxation. The activities of the autonomic nervous system and the sympathetic nervous system are measured by analyzing the power spectrum for the change in the interval. HF (high frequency) indicates the activity of the parasympathetic nervous system, and LF/HF (a ratio of Low Frequency to High Frequency) indicates the balance between the sympathetic and parasympathetic nervous systems. In this study, participants were measured in comfortable sitting positions for three minutes using uBioMacpa(Biosense creative, Seoul, Korea) instruments.

\subsection{Data Analysis}

All statistical analyses were performed using SPSS 21.00 (SPSS, Chicago, IL, USA). A response paired sample t-test was performed to identify changes in psychological wellbeing and HRV between the pre- and post-test. ANCOVA was conducted to compare 
differences between groups (experimental and control). The pretest results were used as covariates (baseline data) to eliminate the effects of different levels of individual psychological well-being and HRV. All statistical tests were performed at a significance level of $p<0.05$.

\section{Results}

\subsection{Psychological Well-Being (Well-Being Manifestation Measure Scale)}

\subsubsection{Results of Measurement for Pre- and Post-Test Psychological Well-Being}

The results of paired t-tests between pre- and post-tests, which verified how affected the psychological well-being for each group presented in Table 3. The results showed that forest therapy programs had a positive effect on the psychological well-being of juvenile probationers. The psychological well-being score of the probationary youth who participated in the forest therapy program increased significantly $(t=-5.64, p=0.000)$. Among the subfactors of psychological well-being, self-esteem $(t=-4.66, p=0.000)$, mental balance $(t=-4.37, p=0.000)$, social involvement $(t=-4.31, p=0.000)$, sociability $(t=-3.13, p=0.004)$, control of self and events $(t=-5.73, p=0.000)$, and happiness $(t=-5.53, p=0.000)$ showed improvement in the mean value improved and showed significant results. Conversely, the control group did not show effects on the psychological well-being of juvenile probationers. Control group did not change significantly, not only in psychological well-being, but also in subfactors such as self-esteem, mental balance, social involvement, sociability, control of self and events, and happiness.

Table 3. Comparison of pre- and post-tests for psychological well-being between the experimental and control groups.

\begin{tabular}{|c|c|c|c|c|c|c|c|}
\hline \multirow[b]{2}{*}{ Variable } & \multirow[b]{2}{*}{ Subfactor } & \multicolumn{3}{|c|}{ Experiment Group $(N=33)$} & \multicolumn{3}{|c|}{ Control Group $(N=17)$} \\
\hline & & $\begin{array}{c}\text { Pretest } \\
M \pm S D\end{array}$ & $\begin{array}{l}\text { Post-Test } \\
M \pm \text { SD }\end{array}$ & $\mathbf{t}$ & $\begin{array}{l}\text { Pretest } \\
M \pm S D\end{array}$ & $\begin{array}{l}\text { Post-Test } \\
M \pm \text { SD }\end{array}$ & $\mathbf{t}$ \\
\hline \multirow{7}{*}{$\begin{array}{l}\text { Psychological } \\
\text { well-being }\end{array}$} & Self-esteem & $3.30 \pm 0.86$ & $4.01 \pm 0.71$ & $-4.66^{* * *}$ & $3.40 \pm 0.77$ & $3.26 \pm 0.73$ & 2.08 \\
\hline & Mental balance & $3.18 \pm 0.83$ & $3.85 \pm 0.70$ & $-4.37^{* * *}$ & $3.33 \pm 0.73$ & $3.22 \pm 0.61$ & 1.13 \\
\hline & Sociability & $3.13 \pm 0.80$ & $3.77 \pm 0.65$ & $-4.31^{* *}$ & $3.34 \pm 0.51$ & $3.21 \pm 0.75$ & 1.09 \\
\hline & Social involvement & $3.48 \pm 0.89$ & $3.96 \pm 0.70$ & $-3.13^{* * *}$ & $3.41 \pm 0.59$ & $3.18 \pm 0.54$ & 0.75 \\
\hline & Control of self and events & $2.97 \pm 0.88$ & $3.83 \pm 0.69$ & $-5.73^{* * *}$ & $3.25 \pm 0.54$ & $3.22 \pm 0.50$ & 1.59 \\
\hline & Happiness & $3.12 \pm 1.01$ & $3.90 \pm 0.61$ & $-5.53^{* * *}$ & $3.47 \pm 0.58$ & $3.24 \pm 0.46$ & 0.27 \\
\hline & Total & $3.19 \pm 0.78$ & $3.90 \pm 0.61$ & $-5.64^{* * *}$ & $3.37 \pm 0.46$ & $3.22 \pm 0.46$ & 2.12 \\
\hline
\end{tabular}

$\mathrm{M}=$ mean; $\mathrm{SD}=$ standard deviation ${ }^{* *} p<0.01^{* * *} p<0.001$ by paired $t$-test.

\subsubsection{Results of Psychological Well-Being Measurement in Each Group}

To examine the effects on juvenile probationers' psychological well-being, a covariance analysis (ANCOVA) was conducted to compare the different values before and after the program experience for each group (see Figure 3). It was confirmed that the forest therapy program resulted in positive changes in psychological well-being $(\mathrm{F}=27.348, p=0.000)$. In the verification of the subfactors of psychological well-being, the experimental group that attended the two-day/one-night forest therapy program showed a positive change in self-esteem $(F=18.018, p=0.000)$, mental balance $(F=14.929, p=0.000)$, social involvement $(\mathrm{F}=10.163, p=0.003)$, sociality $(\mathrm{F}=18.019, p=0.000)$, control of self and events $(\mathrm{F}=17.047$, $p=0.000)$, and happiness $(\mathrm{F}=25.787, p=0.000)$. 


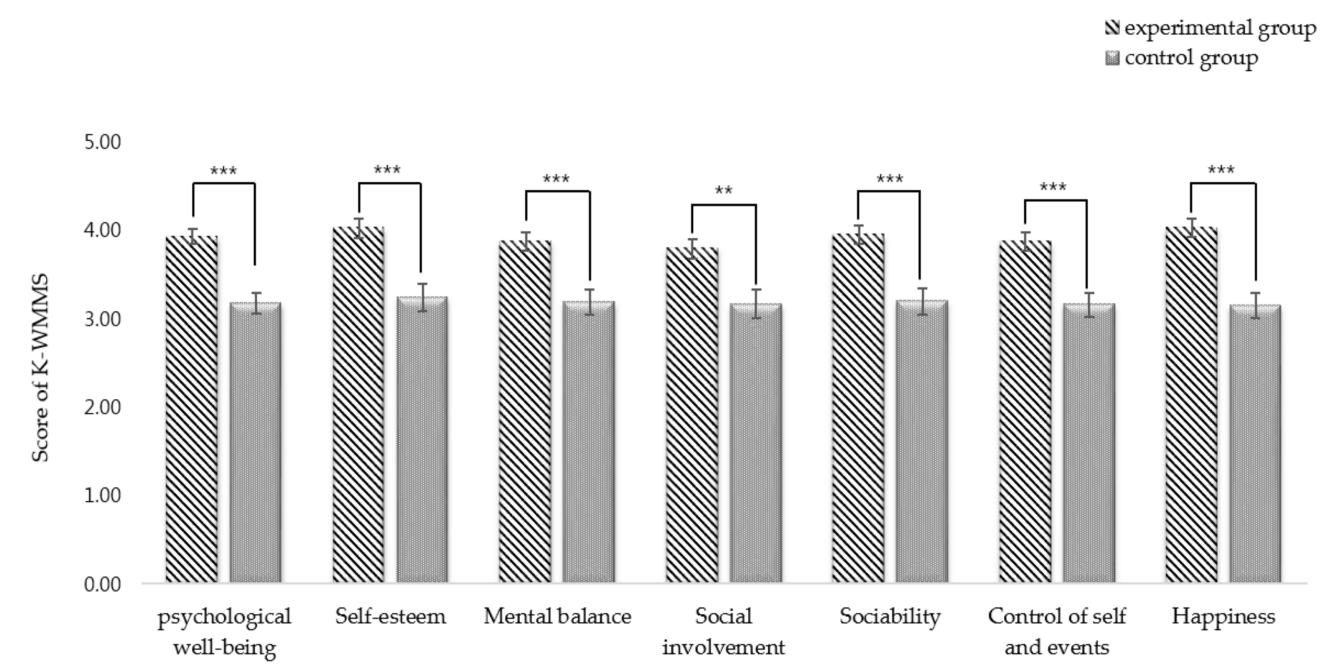

Figure 3. The effect of forest therapy on psychological well-being, comparing experimental and control groups, ${ }^{* *} p<0.01,{ }^{* * *} p<0.001$.

\section{2. $H R V$}

\subsubsection{Measurement Results for Pre- and Post-Test HRV}

The results of paired t-tests between pre- and posttests, which verified how affected the HRV for each group presented in Table 4. HF and LF/HF show the activity of parasympathetic nerves, which is an indicator of HRV. The forest therapy program participation group showed positive changes in $\mathrm{HF}(t=-3.77, p=0.001)$ and LF/HF $(t=4.38, p=0.000)$. The juvenile probationers' activity in the forest was physiologically stable and positively affected. Conversely, the control group did not show effects on the HF or LF/HF of juvenile probationers.

Table 4. Comparison of HRV pre- and posttests between the experimental and control group.

\begin{tabular}{|c|c|c|c|c|c|c|c|}
\hline \multirow{2}{*}{\multicolumn{2}{|c|}{ Variable }} & \multicolumn{2}{|c|}{ Experiment Group $(N=33)$} & \multicolumn{4}{|c|}{ Control Group $(N=17)$} \\
\hline & & $\begin{array}{c}\text { Pretest } \\
\mathbf{M} \pm \mathbf{S D}\end{array}$ & $\begin{array}{c}\text { Post-Test } \\
\mathbf{M} \pm \mathrm{SD}\end{array}$ & $\mathbf{t}$ & $\begin{array}{c}\text { Pretest } \\
\mathbf{M} \pm \mathbf{S D}\end{array}$ & $\begin{array}{c}\text { Post-Test } \\
\mathbf{M} \pm \mathbf{S D}\end{array}$ & $\mathbf{t}$ \\
\hline \multirow{2}{*}{ HRV } & $\mathrm{HF}$ & $6.98 \pm 0.64$ & $7.32 \pm 0.54$ & $-3.77^{* *}$ & $6.91 \pm 0.66$ & $7.03 \pm 0.31$ & -1.15 \\
\hline & $\mathrm{LF} / \mathrm{HF}$ & $1.18 \pm 0.11$ & $1.09 \pm 0.09$ & $4.38^{* * *}$ & $1.20 \pm 0.13$ & $1.15 \pm 0.08$ & 1.37 \\
\hline
\end{tabular}

\subsubsection{Results of HRV Measurement in Each Group}

ANCOVA was conducted to compare the value differences between pre- and postHRVs and identify physiological changes between the different program groups. As a result of HF, a positive change ( $\mathrm{F}=5.280, p=0.026)$ was observed in adolescents who received forest therapy. In the experimental group, LF/HF also showed a positive effect $(\mathrm{F}=4.848, p=0.033)$ (see Figure 4). The forest environment creates comfort for the human body, and this positively affects physiological changes. It has been shown that forest therapy participants can achieve emotional stability through autonomic nervous system balance and parasympathetic nerve activation. 


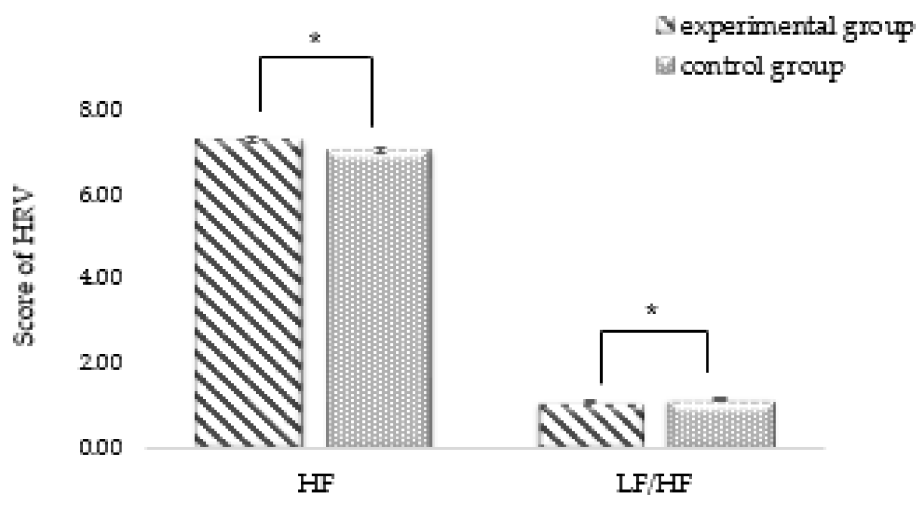

Figure 4. The effect of forest therapy on HRV by comparing experimental and control groups, $* p<0.05$.

\section{Discussion}

This study was conducted to promote the psychological and physical stability of probationary youth by participating in a camp-type forest therapy program, which was organized to reflect their characteristics, for two days and one night. The results of this study showed that the forest therapy program influenced the psychological well-being and physical health of probationary adolescents. Empirical studies show that forest therapy programs, as well as simple activities in the forest, affect the health of participants. However, few studies have reported the psychological and physical effects of forest therapy programs for adolescents under probation. Therefore, this study suggests that these programs can help improve the psychological and physical health of probationary adolescents.

The results of the effectiveness of forest therapy programs for adolescents under probation are as follows: First, the experimental group that received the forest therapy program experienced a significant improvement in psychological well-being after the program. Self-esteem, mental balance, social involvement, sociability, control of self and events, and happiness, which are components of psychological well-being and have greatly improved. However, there were no significant changes in the control group. These results are consistent with prior studies that show that activities in forests have a positive effect on the psychological well-being [63-65]. Kim et al. [63] showed a change in the psychological well-being of high school students who received forest therapy programs using school forests and the attitude toward forests. You et al. [64] reported that a forest therapy program helped relieve psychological well-being, depression, and stress. Lee et al. [65] reported that forest healing programs improved participants' psychological well-being, optimistic personal relationships, autonomy, and purpose of life. Juvenile delinquents experience more negative than positive emotions. According to a study by Shin et al. [66], the forest is a place where one can experience pleasure and self-realization by performing activities that create a sense of accomplishment, exploration, and adventure (in line with the pleasure of flow). This suggests that forests produce a restoration effect, reducing negative emotions and shifting emotional states [40-42]. Furthermore, active forest intervention may have a positive effect on the psychological well-being of probationary adolescents.

Second, the experimental group that received the forest therapy program experienced significant improvement in HRV's HF and LF/HF physiological stability after the forest therapy program. However, there was no significant change in the control group. This was consistent with the findings of prior studies that forest activities provide physiological stability through the activation of parasympathetic nerves [42,46-49,67,68]. A stress is a process by which a person responds with specific physiological responses and actions to situations that threaten their well-being and health [69]. In situations of excitement and stress, sympathetic nerves are activated, increasing heart rate, and maintaining tension; it is, therefore, important to activate the parasympathetic nerves so that the body can stabilize. Woo et al. [67] reported a significant increase in parasympathetic nerves (HF) 
after conducting a forest therapy program for patients with depression. According to Li et al. [68], autonomic neuronal balance (LF/HF) and stress index significantly decreased after experiencing a long-term forest therapy program (six nights and seven days). Activities in the forest help stabilize the body and mind. Quintana et al. [70] reported that the social and cognitive ability to understand other people's feelings, thoughts, etc. was reportedly superior to that of other students when the parasympathetic nerves were activated. Sensitive and nervous adolescents' emotions can negatively affect their physical responses and are thought to have a positive effect on the physiological stability of probationary adolescents with aggressive and spontaneous characteristics.

Third, there was a clear difference between the forest therapy group and the control group. The forest experience not only positively affected the development of social emotions, such as emotional acceptance and improved emotional control of teenagers, but also provided physiological stability. Forest therapy played a role in reducing stress from everyday life. The program intervention, which combines the healing elements of nature to help subjects improve their activities in the forest, is likely to have promoted physical stability changes, increasing their resilience in the natural environment.

The forest therapy experience for probationary youth affected not only their emotional stability, but also their mental and physical resilience. Forest therapy played a role in reducing stress from everyday life. These programs may improve adolescents' positive thinking toward the future along with an increased sensitivity or sense of cooperation with others. All these factors contribute to character development and personal growth. Such programs can play an active role in improving mental health and for reaching target goals for probationary youth. Forest therapy programs are not passive activities. Instead, participants experience the forest through meditation, physical activity, mental and physical relaxation, and ecological education. This mental health service provided to adolescents has a significant impact on delinquency behaviors and reducing recidivism [71,72]. Thus, adolescents with weak social ties and low empathy can experience changes as these programs reduce aggression and encourage group cooperation. Participation in the camp-like forest therapy program may ultimately help with social participation, social improvement, and relationships with others. Adolescence is a time when emotional instability, extreme emotions, and emotional intensity are at their highest point [73]. Considering that this is the time when emotional and physiological health is responsive to psychological stability, the forest therapy program can provide a sense of psychological relaxation. Further implementation as an attendance center orders program will ultimately have a positive effect on crime prevention and juvenile guidance.

Several limitations exist in this study. First, it is difficult to identify and present a suitable period for the effectiveness of participants in the detailed program with a program that lasted for one night and two days. Further research is needed to clarify the effects of the participation period and the continued effectiveness of the program after returning to daily life. Second, the sample size was small, and there are limitations to generalizing the results. Therefore, further research is needed for a variety of participants, depending on the type and motivation, characteristics of the individual offenses. In the case of juvenile delinquents, there are various factors that affect crime. Therefore, different types of interventions are needed. Third, participants' experience, satisfaction, and preferences in the forest can affect the results. Due to the participants' satisfaction with the forest, it can be difficult to see it as an effect of the forest therapy program alone. Fourth, there was minimal control over the daily activities of the control group. The types of activities other than program activity hours in the control group (i.e., academic, family, peer relations, etc.) may have varied, which may have affected the outcome comparison. Fifth, a deeper approach is needed to discuss new possibilities for the psychological and physical wellbeing of probationary adolescents. Additional research using qualitative analysis is needed to understand the process of changes in an individual's emotions and cognition through forest therapy programs. In addition, longitudinal studies on the changes in participants will also be needed. These limitations should be considered for future research. 
Nevertheless, this study is significant in that it verified the applicability and effectiveness of forest therapy programs with special groups of youth guardians. Future studies should organize various forms of forest therapy programs tailored to the individual needs and goals of probationary youth. It is reported that the forest therapy program will contribute to the social and emotional development of probationary youth, which is the purpose of the probation system.

\section{Conclusions}

The results of this study show that forest therapy can help improve the psychological and physiological symptoms of emotionally unstable juvenile probationers, who are establishing themselves in various experiences at this stage of life. Therefore, forest therapy can contribute to emotional stability and health promotion if it is used to manage psychological stability.

Author Contributions: J.Y.J. performed data acquisition, statistical analysis, interpretation of the results, and manuscript preparation. I.O.K. was involved with data acquisition and performed a forest therapy program. P.-s.Y. contributed to statistical data analysis and interpreted the results. W.S.S. led the research process, experimental design, interpretation of results, and manuscript preparation and editing. All authors have read and agreed to the published version of the manuscript.

Funding: This research received the support of "juveniles on probation forest education consignment business" provided by the Korea Forest Service.

Institutional Review Board Statement: This study was conducted with the approval of the IRB (CBNU-201809-SB-711-01) of Chungbuk National University Industry-Academic Cooperation Foundation.

Informed Consent Statement: Informed consent was obtained from all subjects involved in the study.

Data Availability Statement: The data presented in this study are available on request from the corresponding author. The data are not publicly available due to privacy.

Acknowledgments: We offer profound thanks to the forest therapy instructors for their valuable guidance.

Conflicts of Interest: The authors declare no conflict of interest.

\section{References}

1. Lee, I.G. On the Measures to Ensure the Effectiveness of the Korean Boys' Probation System-Focusing on the Need for Legal Education. Law Rev. 2020, 20, 313-341.

2. Park, H.H.; Kim, J.H. A Study on the Discussion of the Amendment of the Juvenile Act-Focussing on the Reinforcement of Juvenile Protection Ideology. Dong A Law Rev. 2018, 78, 1-26. [CrossRef]

3. Korean National Police Agency. Crime Phenomenon and Criminal Policy in Korea (2019); Korean National Police Agency: Seoul, Korea, 2020.

4. Institute of Justice. The White Paper on Crime 2019; Institute of Justice: Jincheon, Korea, 2020.

5. Erikson, E.H. Identity Youth and Crisis; WW Norton: New York, NY, USA, 1968.

6. Ryff, C.D. Happiness is everything, or is it? Explorations on the meaning of psychological well-being. J. Personal. Soc. Psychol. 1989, 57, 1069-1081. [CrossRef]

7. Kim, M.S.; Kim, H.W.; Cha, K.H. Analyses on the Construct of Psychological Well—Being (PWB) of Korean Male and Female Adults. Korean J. Soc. Personal. Psychol. 2001, 13, 19-39.

8. Armsden, G.C.; Greenberg, M.T. The Inventory of Parent and Peer Attachment: Individual Difference and Their Relationship to Psychological Well-Being in Adolescence. J. Youth Adolesc. 1987, 15, 227-254. [CrossRef] [PubMed]

9. Kim, A.K.; Kim, S.B. Effects of Parent Attachment, Peer Attachment, Teacher Attachment, and Ego Resilience on Adolescents' School Life Adjustment. Korean J. Youth Stud. 2018, 25, 273-297. [CrossRef]

10. Laird, R.D.; Criss, M.M.; Pettit, G.S.; Dodge, K.A.; Bates, J.E. Parents' monitoring knowledge attenuates the link between antisocial friends and adolescent delinquent behavior. J. Abnorm. Child Psychol. 2008, 36, 299-310. [CrossRef]

11. Ingram, J.R.; Patchin, J.W.; Huebner, B.M.; McCluskey, J.D.; Bynum, T.S. Parents, friends, and serious delinquency: An examination of direct and indirect effects among at-risk early adolescents. Crim. Justice Rev. 2007, 32, 380-400. [CrossRef]

12. Ciarrochi, J.; Morin, A.J.; Sahdra, B.K.; Litalien, D.; Paker, P.D. A longitudinal person-centered perspective on youth social support: Relations with psychological wellbeing. Dev. Psychol. 2017, 53, 1154-1169. [CrossRef] 
13. Shader, M. Risk Factors for Delinquency: An Overview; Department of Justice, Office of Justice Programs, Office of Juvenile Justice and Delinquency Prevention: Washington, DC, USA, 2003.

14. McCord, J.; Widom, C.S.; Crowell, N.A. Juvenile Crime, Juvenile Justice. Panel on Juvenile Crime: Prevention, Treatment, and Control; National Academy Press: Washington, DC, USA, 2001.

15. Chin, T.W.; Kim, S.J.; Lee, H.P.; Cho, S.C. The influence of family environment and moral development to conduct disorder in adolescents. J. Korean Acad. Child Adolesc. Psychiatry 1997, 8, 163-174.

16. McPhail, L.M. Early Intervention for Stealing: Interrupting the Antisocial Trajectory. Master's Thesis, University of Canterbury, Christchurch, New Zealand, 2008.

17. Lee, E.G.; Han, S.Y. Effects of Affection, Monitoring and Inconsistent Parenting on the Emotional Problems of Children and Adolescents. Korean J. Hum. Dev. 2016, 23, 153-172.

18. Lee, S.M. The Effects of Deviant Peer on Delinquency: The Difference of Gender and an Opposite Sex Peer. J. Korean C. Assoc. 2018, 12, 47-71.

19. Son, S.O.; Lee, B.J. A Study of Influencing Factors of adolescent social relations: Examining the Mediating Effects of Aggression and Depression, and gender differences. Korean J. Youth Stud. 2015, 22, 1-26.

20. Cheng, H.; Furnham, A. Personality, self-esteem, and demographic predictions of happiness and depression. Personal. Individ. Differ. 2003, 34, 921-942. [CrossRef]

21. Levy, K. The relationship between adolescent attitudes towards authority, self-concept, and delinquency. Adolescence 2001, 36, 333-346.

22. Farrington, D.P.; Biron, L.; LeBlane, M. Personality and delinquency in London and Montreal. In Abnormal Offenders, Delinquency, and the Criminal Justice System; Gunn, J.C., Farrington, D.P., Eds.; Wiley: New York, NY, USA, 1982.

23. Achenbach, T.M. Manual for the Child Behavior Checklist/4-18 and 1991 Profile; University of Vermont: Burlington, VT, USA, 1991.

24. Tremblay, R.E.; Nagin, D.S.; Séguin, J.R.; Zoccolillo, M.; Zelazo, P.D.; Boivin, M.; Pérusse, D.; Japel, C. Physical aggression during early childhood: Trajectories and predictors. Pediatrics 2004, 114, e43-e50. [CrossRef]

25. Park, B.S.; Bae, S.W.; Jin, H.M. The impact of informal Labeling, self-esteem, depression, and aggression on juvenile delinquencyFocusing on path analysis. J. Adolesc. Welf. 2011, 13, 121-148.

26. Park, D.J.; Kim, N.Y. Mediating Effects of Self-Esteem on the Effects of Social Stigma on Depression of Out-of-School Adolescents. J. Youth Act. 2019, 5, 71-87.

27. Anderson, E. The code of the streets. Atl. Mon. 1994, 273, 81-94.

28. Lim, J.S.; Han, M.I.; Han, E.Y. Factors Influencing the Aggression Levels of Juvenile Offenders Using the Heckman Selection Model. Stud. Korean Youth 2009, 20, 29-69.

29. De Wilde, E.J.; Kienhorst, C.W.; Diekstra, R.F.W.; Wolters, W.H.G. The relationship between adolescent suicidal behavior and life event in childhood and adolescence. Am. J. Psychiatry 1992, 149, 45-51. [PubMed]

30. Nam, J.S. The Relationship between Participation in Leisure Sports Activities of middle and high School Students and Pro-Social Behavior. Master's Thesis, Kyung Hee University, Seoul, Korea, 2004.

31. Wheaton, B. Models for the stress-buffering functions of coping resources. J. Health Soc. Behav. 1985, 26, 352-364. [CrossRef]

32. Seo, J.Y.; Kim, M.Y. Stress, physical symptoms, and coping styles of high school students. Child Health Nurs. Res. 2006, $12,470-477$.

33. Bang, K.S.; Lee, I.S.; Kim, S.J.; Yoon, J.H.; Lee, J. A Comparison of Mental Health of School Age Children between Urban and Rural Area and a Correlation Analysis of Subjective Mental Health Indicators and Heart Rate Variability. J. Korean Soc. Sch. Health 2017, 30, 266-273.

34. Lee, M.S. Current Status and Vitalization Plan of Juvenile Probation. Korean Juv. Prot. Rev. 2020, 33, $159-185$.

35. Lee, G.Y.; Choi, J.H.; Song, J.Y.; Jeon, J.H. The effectiveness of prevention program of recidivism for school violence on juvenile probation focusing on the empathy development training program. Korean J. Probat. 2013, 13, 249-274.

36. Kweon, H.S. The effect of a mentoring program on fostering positive development capabilities in juveniles under probation. $J$. Korea Inst. Youth Facil. Environ. 2014, 12, 81-92.

37. Lee, J.H.; Ryu, J.M. The effect of group art therapy using mandala for emotional stabilization and attentiveness of juvenile delinquents. Korean J. Arts Ther. 2014, 14, 41-66.

38. Kim, I.S. Tea-culture therapy program development to alleviate the aggressiveness of the juvenile probationers. Korean J. Probat. 2017, 1, 123-151.

39. Lee, Y.J.; Jeong, Y.J.; Park, S.Y.; Choi, S.J. Study on the Status of Educational Guidance of At-Risk Youths and Measures Enhance its Efficacy; National Youth Policy Institute: Sejong, Korea, 2018.

40. Park, B.J.; Furuya, K.; Kasetani, T.; Takayama, N.; Kagawa, T.; Miyazaki, Y. Relationship between psychological responses and physical environment in forest settings. Landsc. Urban Plan. 2011, 102, 24-32. [CrossRef]

41. Takayama, N.; Korpela, K.; Lee, J.; Morikawa, T.; Tsunetsugu, Y.; Park, B.-J.; Li, Q.; Tyrväinen, L.; Miyazaki, Y.; Kagawa, T. Emotional, restorative and vitalizing effects of forest and urban environments at four sites in Japan. Int. J. Environ. Res. Public Health 2014, 11, 7207-7230. [CrossRef] [PubMed]

42. Lee, J.; Park, B.J.; Tsunetsugu, Y.; Ohira, T.; Kagawa, T.; Miyazaki, Y. Effect of forest bathing on physiological and psychological responses in young Japanese male subjects. Public Health 2011, 125, 93-100. [CrossRef]

43. Jung, W.H.; Woo, J.M.; Rye, J.S. Effect of a forest therapy program and the forest environment on female workers' stress. Urban For. Urban Green. 2015, 14, 274-281. [CrossRef] 
44. Lee, J.W.; Yeon, P.S.; Park, S.H.; Kang, J.W. Effects of a forest therapy program on the stress and emotional change of emotional labor workers. J. Korean Inst. For. Recreat. 2018, 22, 13-22.

45. Hong, J.; Park, S.; Lee, J. Changes in depression and stress of the middle-aged and elderly through participation in a forest therapy program for dementia prevention. J. People Plants Environ. 2019, 22, 699-709. [CrossRef]

46. Park, B.J.; Tsunetsugu, Y.; Kasetani, T.; Kagawa, T.; Miyazaki, Y. The physiological effects of Shinrin-yoku (taking in the forest atmosphere or forest bathing): Evidence from field experiments in 24 forests across Japan. Environ. Health Prev. Med. 2010, 15, 18-26. [CrossRef]

47. Park, B.J.; Tsunetsugu, Y.; Ishii, H.; Furuhashi, S.; Hirano, H.; Kagawa, T.; Miyazaki, Y. Physiological effects of Shinrin-yoku (taking in the atmosphere of the forest) in a mixed forest in Shinano Town, Japan. Scand. J. For. Res. 2008, 23, 278-283. [CrossRef]

48. Park, B.J.; Kasetani, T.; Morikawa, T.; Tsunetsugu, Y.; Kagawa, T.; Miyazaki, Y. Physiological effects of forest recreation in a young conifer forest in Hinokage Town, Japan. Silva Fenn. 2009, 43, 291-301. [CrossRef]

49. Tsunetsugu, Y.; Park, B.J.; Ishii, H.; Hirano, H.; Kagawa, T.; Miyazaki, Y. Physiological effects of "Shinrin-yoku" (taking in the atmosphere of the forest) in an old-growth broadleaf forest in Yamagata prefecture, Japan. J. Physiol. Anthropol. 2007, 26, 135-142. [CrossRef]

50. Tsunetsugu, Y.; Park, B.J.; Miyazaki, Y. Trends in research related to "Shinrin-yoku" (taking in the forest atmosphere or forest bathing) in Japan. Environ. Health Prev. Med. 2010, 15, 27-37. [CrossRef]

51. Oh, K.H.; Kim, D.J.; Kim, J.G.; Kim, Y.S. The effects of forest-healing program on developing Youth activity competence. Korean J. Youth Stud. 2016, 23, 1-24. [CrossRef]

52. Chang, J.S.; Kim, N.Y.; Lee, S.H.; Kim, B.S. The Forest Experience Program and Improvement of Depression, Anxiety, and Self-concept in Adolescents. J. Korean For. Soc. 2015. 104, 127-132. [CrossRef]

53. Cho, Y.M.; Kim, D.J.; Yeon, P.S.; Kwon, H.K.; Cho, H.S.; Lee, J.M. The influence of a seasonal forest education program on psychological well-being and stress of adolescents. J. Korean Inst. For. Recreat. 2014, 182, 59-69.

54. Lee, J.A. Study on the Stress Relief Effects of Adolescent Physical Activity in City Parks. Ph.D. Thesis, Seoul National University, Seoul, Korea, 2017.

55. Chung, A.S.; Choi, S.W.; Woo, J.M.; Mok, J.Y.; Kim, K.W.; Park, B.J. The Effect of Short-term Forest Therapy Camp on Youths with Internet Addiction Risk Group: Focused on the Biological, Neurocognitive and Psychosocial Aspects. J. Korean Soc. For. Sci. 2015, 104, 657-667. [CrossRef]

56. Eom, M.S.; Lee, Y.H.; Ha, S.Y. Effect of Forest Education Program on Juvenile Probationers' Mood States, Self-esteem, and Self Control. J. Korean Soc. For. Sci. 2016, 105, 253-260.

57. Jang, J.; Lee, Y.H.; Ha, S.Y. A Study on Effect of Forest Education Program for Juvenile Probationers. J. People Plants Environ. 2017, 20, 271-282. [CrossRef]

58. Walsh, M.A. Wilderness Adventure Programming as an Intervention for Youthful Offenders: Self-Efficacy, Resilience, and Hope for the Future. Ph.D. Thesis, University of Minnesota Digital Conservancy, Minneapolis, MN, USA, 2009.

59. Ha, S.Y.; Lee, Y.H.; Eom, M.S. Forest Education for Juvenile Probationers, KFRI Forest Policy Issues; Bulletin 50; National Institute of Forest Science: Seoul, Korea, 2015.

60. Yoon, C.K.; Kim, H.J.; Kim, B.K.; Jeong, D.J.; Ha, S.Y.; Lee, Y.H.; Choi, I.S.; Son, J.W. Study on the Development and Management of a Forest Experience Program to Support the Growth of the Youth at Risk; National Research Council for Economics, Humanities and Social Sciences: Sejong, Korea, 2014.

61. Park, E.J.; Choi, S.M. The study on a validation of well-being manifestation measure scale in Korea. Korea Youth Res. Assoc. 2014, 21, 495-511.

62. Masse, R.; Poulin, C.; Dassa, C.; Lambert, J.; Belair, S.; Battaglini, M.A. Elaboration and validation of a tool to measure psychological well-being: WBMMS. Can. J. Public Health Revue Can. Sante Publique 1997, 89, 352-357.

63. Kim, H.R.; Koo, C.D. The Influence of Urban Forest and School Forest Experience Activities on Attitude Toward Forest, Psychological Well-being and Stress of High School Student. Korean J. Environ. Ecol. 2019, 33, 341-353. [CrossRef]

64. You, Y.S.; Kim, H.C.; Lee, C.J.; Jang, N.C.; Son, B.K. A Study of Effects of Sallimyok (Forest Therapy)-based Mental Health Program on the Depression the Psychological Stability. J. Korean Soc. Sch. Community Health Educ. 2014, 15, 55-65.

65. Lee, M.N.; Song, J.S. The Effects of Prenatal Education in Forest on the Mindfulness and Psychological Well-Being of Pregnant Woman. J. Korean Inst. For. Recreat. 2015, 19, 25-34.

66. Shin, W.S. Socialization of Forests; Ddanim: Seoul, Korea, 2003.

67. Woo, J.M.; Kim, W.; Park, S.M.; Lim, S.K. Synergistic Effect of Forest Environment and Therapeutic Program for the Treatment of Depression. J. Korean For. Soc. 2012, 101, 677-685.

68. Lee, B.; Park, C.H.; Park, S.J. Effect of Long-Term Stay Forest Therapy Program on User's Positive and Negative Emotions and Physical Changes. J. Korean For. Soc. 2020, 109, 544-552.

69. Ulrich, R.S.; Simons, R.F.; Losito, B.D.; Fiorito, E.; Miles, M.A.; Zelson, M. Stress recovery during exposure to natural and urban environments. J. Environ. Psychol. 1991, 11, 201-230. [CrossRef]

70. Quintana, D.S.; Guastella, A.J.; Outhred, T.; Hickie, I.B.; Kemp, A.H. Heart rate variability is associated with emotion recognition: Direct evidence for a relationship between the autonomic nervous system and social cognition. Int. J. Psychophysiol. 2012, 86, 168-172. [CrossRef] 
71. Foster, E.; Qaseem, A.; Connor, T. Can better mental health services reduce the risk of juvenile justice system involvement? Am. J. Public Health 2004, 94, 859-865. [CrossRef]

72. Yoder, J.R.; Whitaker, K.; Quinn, C.R. Perceptions of recidivism among incarcerated youth: The relationship between exposure to childhood trauma, mental health status, and the protective effect of mental health services in juvenile justice settings. Adv. Soc. Work 2017, 18, 250-269. [CrossRef]

73. Berger, K.S. The Developing Person: Through Childhood and Adolescence; Worth Publishers: New York, NY, USA, 2005. 